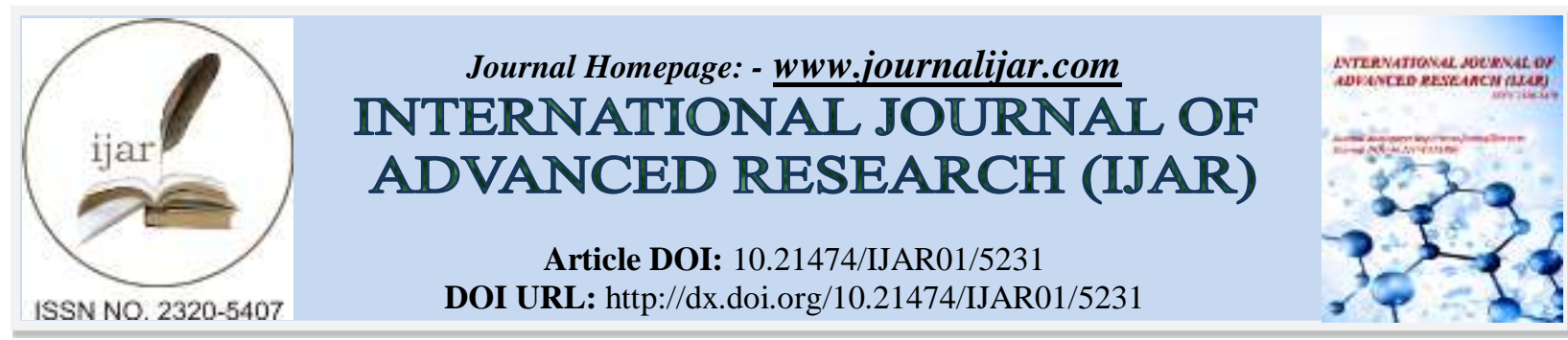

RESEARCH ARTICLE

\title{
FIRST DERIVATIVE SPECTROPHOTOMETRY FOR SIMULTANEOUS DETERMINATION OF IRON AND CALCIUM USING BROMOPYROGALLOL RED.
}

\author{
Amin K. Qasim and Lazgin A. Jamil. \\ Faculty of Science, Department of Chemistry, University of Zakho, P.O. Box 12, Zakho-Duhok, Kurdistan Region, \\ Iraq.
}

\section{Manuscript Info}

Manuscript History

Received: 21 June 2017

Final Accepted: 23 July 2017

Published: August 2017

Key words:-

Iron, Calcium, First Derivative

Spectrophotometry, BPR.

\begin{abstract}
Bromopyrogallol Red (BPR) as analytical reagent has been used for simultaneous determination of iron and calcium using first-derivative spectrophotometry. The zero - crossing technique was employed using first-derivative for Fe-BPR and Ca-BPR at $600 \mathrm{~nm}$ and $558 \mathrm{~nm}$ respectively. The linear relationship for $\mathrm{Fe}$ and $\mathrm{Ca}$ determination obeys beer's law from $0.2-1.2 \mu \mathrm{g} / \mathrm{ml}$ and $0.2-1.0 \mu \mathrm{g} / \mathrm{ml}$ respectively. The proposed method should be useful for accurate, precise, and rapid determination of iron and calcium in various samples with percentage recovery of about $101 \%$.

The stability constants (mean of three values) were found to be $1.33 \times 10^{8} \mathrm{~L}^{2} \cdot \mathrm{mol}^{-2}$ and $9.13 \times 10^{11} \mathrm{~L}^{2} \cdot \mathrm{mol}^{-2}$ for Fe-BPR and Ca-BPR complexes respectively which indicates that the complexes are stable.
\end{abstract}

Copy Right, IJAR, 2017,. All rights reserved.

\section{Introduction:-}

Derivative spectrophotometry in the UV-Vis region is a useful technique in extracting qualitative and quantitative information from overlapping bands of the analyst and interference due to incompletely resolve peaks. A number of studies were reported showing the advantage order spectrophotometry[1].

Derivative spectrophotometric methods have been used for the quantitative analysis of complex mixture because of their great sensitivity and selectivity as well as useful means of resolving two overlapping spectra and eliminating matrix interferences in the assay of two-component mixtures using the zero-crossing technique [2].

Iron and calcium are metals which appear together almost in several samples, both natural and artificial. In most cases, the characterization of these samples includes the determination of their metal ion content. The need for iron and calcium analysis in environmental and biochemical material has increased after reports on different roles of these metals in human health, diseases and industrials [3]. Since of the simultaneous presence of iron and calcium in many real samples, selective analytical techniques and methods have been put forward for simultaneous determination of both elements. Some simultaneous determination techniques and methods are derivative spectrophotometry, atomic absorption spectrometry, sequential flow injection technique, high-performance liquid chromatography, H-point standard addition and partial least squares methods. Among the proposed methods for simultaneous determination of species, derivative spectrophotometry has shown some advantages such as simplicity, speed, sensitivity and selectivity[4]. Derivative spectrophotometry has been used for the simultaneous determination of inorganic ions through the formation of their complexes with the same organic ligand. Some examples are mentioned in chapter one. 


\section{Experimental:-}

Apparatus:-

Spectral and absorbance measurements were carried out using UNICAM, He $\lambda$ IOS $\beta$ UV-Vis computerized single beam spectrophotometer Connected with hp laser Jet 1200 Series printer. The $\mathrm{pH}$ measurements were made by using both Cyber Scan 510 pc.PH meter with a combined glass electrode.

2.2. Reagents

All chemicals used were of the highest purity available. Double distilled deionizer water was used throughout this study and its dilution. Glass vessels were cleaned by double distilled water. And BPR reagent $(3.6 \times 10-4 \mathrm{M})$ was prepared by dissolving $0.0207 \mathrm{gm}$ of BPR (Hopkins and William/Ltd) in double distilled water and the volume was made to $100 \mathrm{ml}$ in volumetric flask and kept in dark bottle.

2.2.1. Stock Iron (III) (100 ppm) solution

This solution was prepared by dissolving 0.723 gm of Ferric nitrate $\mathrm{Fe}\left(\mathrm{No}_{3}\right)_{3} \cdot 9 \mathrm{H}_{2} \mathrm{O}$ ( Fluka) in double distilled water and few drops of nitric acid (S.p.gr.1.41,65\%)(Alpha $\alpha$ ) were added to convert all $\mathrm{Fe}^{2+}$ to $\mathrm{Fe}^{3+}$. The solution was completed to $1000 \mathrm{ml}$ volumetric flask. The working iron $(10 \mathrm{ppm})$ solution $\left(1.79 \times 10^{-4} \mathrm{M}\right)$ was prepared by diluting $10 \mathrm{ml}$ of the above solution to $100 \mathrm{ml}$ with double distilled water in a volumetric flask.

2.2.2. Stock calcium (II) (100 ppm) solution

This solution was prepared by dissolving $0.546 \mathrm{gm}$ of calcium chloride hydrous $\mathrm{CaCl}_{2} \cdot 2 \mathrm{H}_{2} \mathrm{O}$ (Analar $\mathrm{BDH}$ ) in double distilled water and a few drops of $\mathrm{HCl}$ were added to prevent "plating out". The solution was completed to $1000 \mathrm{ml}$ volumetric flask. The working calcium $(10 \mathrm{ppm})$ solution $(2.492 \times 10-5 \mathrm{M})$ was prepared by diluting $10 \mathrm{ml}$ of the above solution to $100 \mathrm{ml}$ with double distilled water in a volumetric flask.

2.2.3. Buffer ( $\mathrm{pH} \mathrm{10)} \mathrm{solution} \mathrm{(phosphate} \mathrm{buffer)}$

The solution contained $50 \mathrm{ml} 0.05 \mathrm{M} \mathrm{Na} 2 \mathrm{HPO} 4$ with $2.2 \mathrm{ml}$ of $0.1 \mathrm{M} \mathrm{NaOH}$. The solution was prepared with double distilled water and completed to $100 \mathrm{ml}$ in volumetric flask [5].

\section{Recommended procedure:-}

For the simultaneous determination of iron and calcium, a sample or standard solution containing 5-30 $\mathrm{g} \mathrm{ml}^{-1}$ of iron and $5-25 \mu \mathrm{g} \mathrm{ml}^{-1}$ of calcium was placed in a calibrated $25 \mathrm{ml}$ flask. $5 \mathrm{ml}$ of reagent solution and $2 \mathrm{ml}$ of sodium hydrogen phosphate was added to the mixture. Then the $\mathrm{pH}$ of the solution was adjusted to 10. Finally, the volume was made with $25 \mathrm{ml}$ with deionize distilled water.

Fig. (1) show that Beer's law was obeyed in the concentration range 0.2-1.2 $\mu \mathrm{g} / \mathrm{ml}$ and $0.2-1.0 \mu \mathrm{g} / \mathrm{ml}$ for determination of iron and calcium respectively.

\subsubsection{First-derivative (ID) measurement}

The first derivative absorption spectra of the Fe-BPR and Ca-BPR complexes in the basic media against a reagent blank were recorded. Zero-crossing wavelengths in the first-derivative spectra of Fe-BPR and Ca-BPR that can be used for their sensitive simultaneous determination were $(600 \mathrm{~nm})$ and $(558 \mathrm{~nm})$, respectively, and comparing the value with appropriate calibration graph in as Fig. (1). In the zero-crossing derivative method, it is necessary that zero-crossing wavelengths do not change with varying concentrations of the related species.

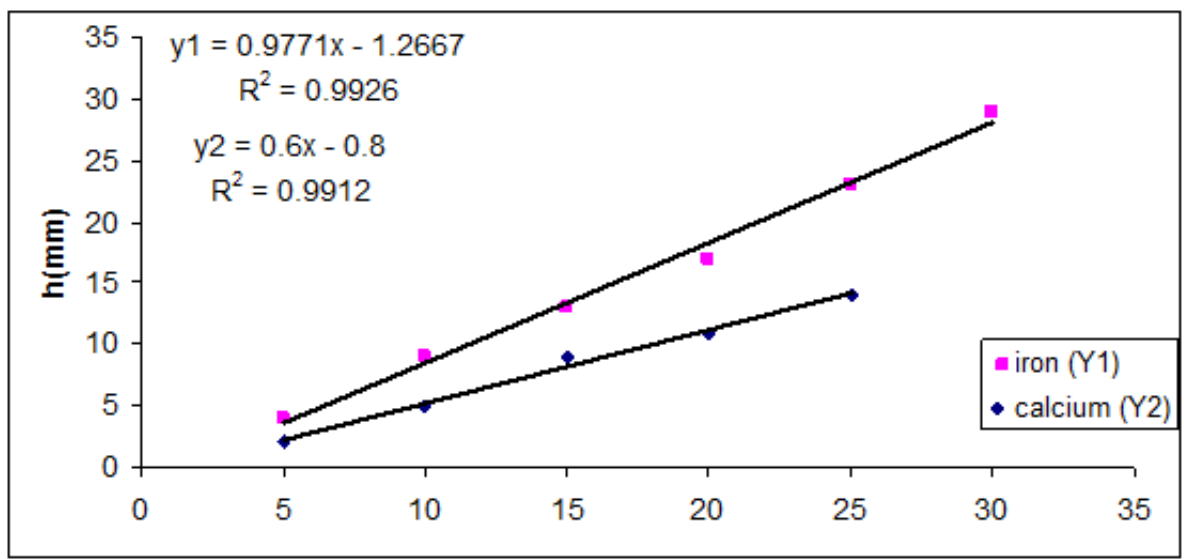

Fig. 1:- First-derivative signal height vs. concentration calibration graph for $\mathrm{Fe}$ and $\mathrm{Ca}$ complexes with $\mathrm{BPR}$ reagent. 
Table 1:- The optimum condition and parameter of derivative spectra

\begin{tabular}{|l|l|}
\hline Parameter & Value \\
\hline Speed & $1200 \mathrm{~nm} / \mathrm{min}$ \\
\hline Data interval & $4.0 \mathrm{~nm}$ \\
\hline Band width & $2.0 \mathrm{~nm}$ \\
\hline Order of addition & {$[\mathrm{M}+\mathrm{B}+\mathrm{R}]$} \\
\hline BPR reagent $\left(3.6 \times 10^{-4} \mathrm{M}\right)$ & $5 \mathrm{ml}$ \\
\hline Buffer solution $(\mathrm{pH} 10)$ & $2 \mathrm{ml}$ \\
\hline
\end{tabular}

\section{Results and discussion:-}

\section{Effect of experimental variability:-}

The effects of various parameters on the simultaneous determination of iron and calcium were investigated. One of the most important parameters was $\mathrm{pH}$. Experiments in various $\mathrm{pH}$ show that the spectra of $\mathrm{BPR}, \mathrm{Fe}-\mathrm{BPR}$ and $\mathrm{Ca}-$ BPR complexes depended on the $\mathrm{pH}$ of the solution. The shape of the absorption spectra, maximum wavelengths and molar absorptivity's changed considerably when $\mathrm{pH}$ varied from 9 to 11 for iron and from 8 to 10.5 for calcium. The shape and maximum wavelengths of the spectra of iron and calcium complexes did not change at $\mathrm{pH} 10$. Optimization of the other parameters such as BPR, Speed, Data interval, Band width and order of addition was performed spectrophotometrically for iron at $600 \mathrm{~nm}$ and for calcium at $558 \mathrm{~nm}$.

\section{Spectrophotometric measurement:-}

Zero-order absorption spectra of iron and calcium showed certain overlapping that interfere with the direct simultaneous determination of this formulation[6]. The normal spectra of Fe (III)-BPR complex and Ca(II)-BPR complex in the presence of sodium phosphate buffer shows the absorbance maxima at $600 \mathrm{~nm}$ and $558 \mathrm{~nm}$, respectively. The absorption spectrum of the mixture of iron and calcium was $548 \mathrm{~nm}$ as shown in curve Fig. $2 \mathrm{c}$ Since the spectral bands of complexes overlap, the determination of iron and calcium in their mixtures by zero-order (normal spectra) is frequently difficult. By using $1^{\text {st }}$ derivative spectrophotometry, these samples can be analysed simultaneously.

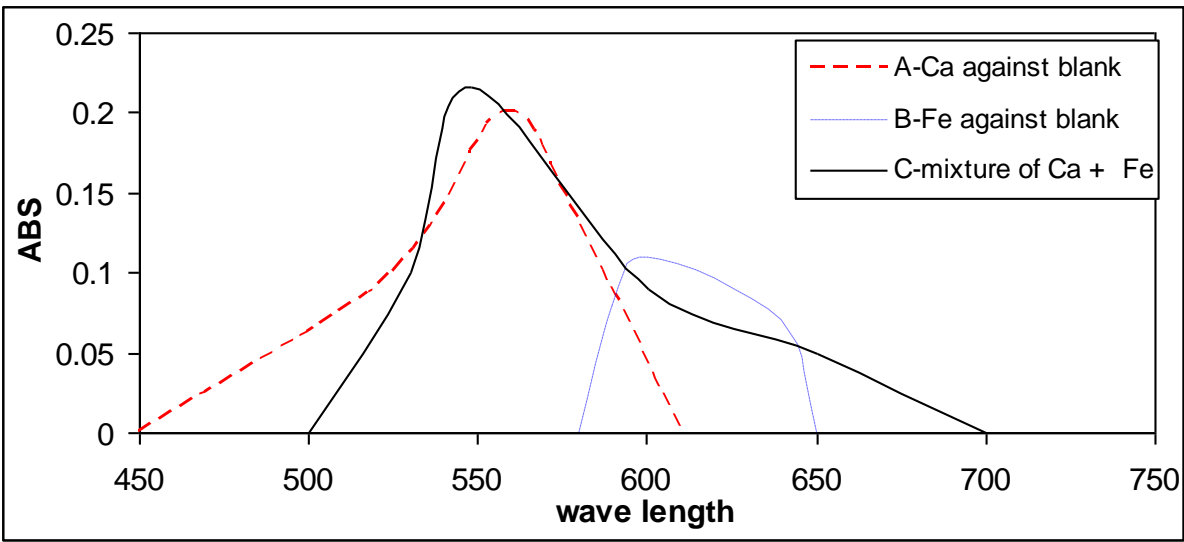

Fig. 2:- Absorption spectra of the BPR complexes of (A) $\mathrm{Ca}$, (B) Fe and (C) mixture of $\mathrm{Fe}$ and $\mathrm{Ca}$. $[\mathrm{Fe}]=20 \mu \mathrm{g}$ of $\mathrm{Fe}$ (III) $/ 25 \mathrm{ml}$ and $[\mathrm{Ca}]=15 \mu \mathrm{g}$ of $\mathrm{Ca}(\mathrm{II}) / 25 \mathrm{ml}$.

First-derivative spectrophotometry:-

The first derivative is a plot of the gradient $\mathrm{dA} / \mathrm{d} \lambda$ of the absorption envelope versus wavelength. Derivative spectra can be produced by processing the spectrophotometer output. The use of derivative spectra can increase the detection sensitivity of minor spectra features and reduce the error caused by the overlap of the analyte spectral band by interfering bands of other species in the sample[7]. Fig (3) and Fig (4) shows the $1^{\text {st }}$-derivative absorption spectra of the complexes of $\mathrm{Fe}$ and $\mathrm{Ca}$ with BPR and of a mixture of both complexes respectively. 


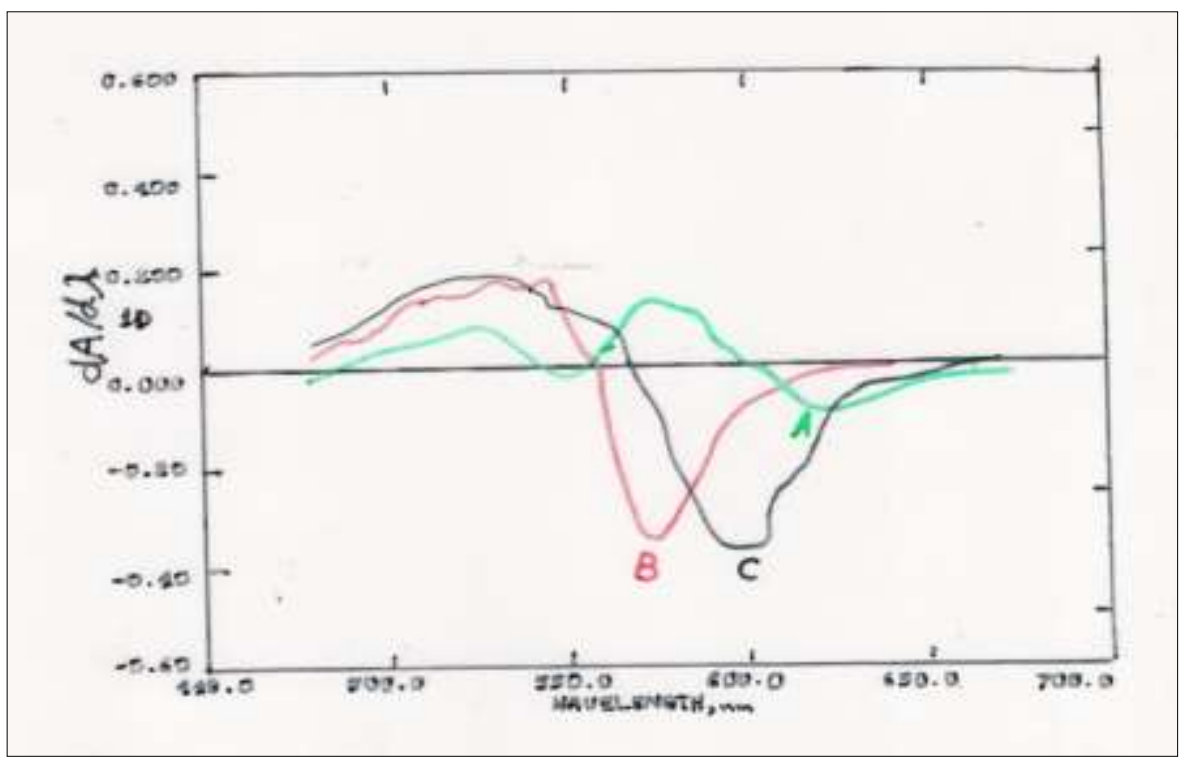

Fig. 3:- First-derivative signal height of the BPR complexes of (A)Fe, (B)Ca and (C)mixture of $\mathrm{Ca}$ and $\mathrm{Fe}$.
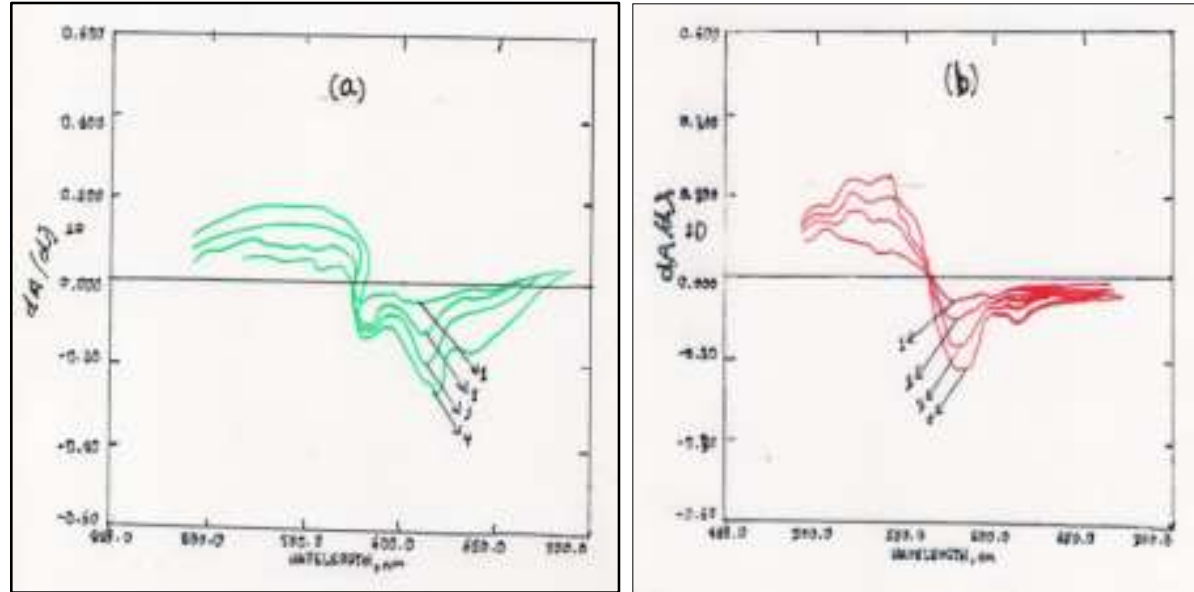

Fig. 4:- First derivative spectra of the solutions containing: a) fixed $10 \mu \mathrm{g} \mathrm{mL}^{-1}$ Calcium and $1: 10 \mu \mathrm{g} \mathrm{mL}^{-1}, 15 \mu \mathrm{g}$ $\mathrm{mL}^{-1}, 20 \mu \mathrm{g} \mathrm{mL}^{-1}$ and $25 \mu \mathrm{g} \mathrm{mL}^{-1}$ iron. b) fixed $10 \mu \mathrm{g} \mathrm{mL}^{-1}$ iron and $1: 10 \mu \mathrm{g} \mathrm{mL}^{-1}, 15 \mu \mathrm{g} \mathrm{mL}^{-1}, 20 \mu \mathrm{g} \mathrm{mL}^{-1}$ and $25 \mu \mathrm{gmL}^{-1}$ calcium Conditions: $25 \mathrm{mLof}$ solution containing $2 \mathrm{ml}$ of buffer $\mathrm{pH} 10$ and $5 \mathrm{ml}$ of reagent $\left(3.6 \times 10^{-4} \mathrm{M}\right)$.

\section{Selection of optimum instrumental conditions:-}

Instrumental parameters such as $\Delta \lambda$, band width and scan speed were optimized to give a constant position of isodifferential/zero cross-over points. The optimum $\Delta \lambda$ for the first derivative was found to be $4.0 \mathrm{~nm}$. A scan speed of $1200 \mathrm{~nm} / \mathrm{min}$ and band width of $2 \mathrm{~nm}$ was found suitable for simultaneous determination of iron and calcium. Response time was automatically selected by the spectrophotometer in accordance with the optical energy and speed of scan. And the noise level decreased with an increase in $\Delta \lambda$.

\section{Analytical determination:-}

Simultaneous determination of Fe and Ca by $1^{\text {st }}$-derivative spectrophotometry in the milk.

Milk products are a very important human nutrient since their consumption has increased in recent years. Milk contains a large variety of essential nutrients for the development and maintenance of a salutary life. This product contains a complex mixture of minerals, including calcium, magnesium, sodium, potassium, chloride, iron, and phosphate. Calcium in milk is distributed between the milk serum and the casein micelles. Calcium is an essential macronutrient for humans, which represents approximately $2 \%$ of body weight in an adult person. This element has mainly a structural function in bones and teeth, and also to regulate many vital biological functions[8]. The iron content of milk is of physiological interest. It is the only source of iron for the child for about 10 months[9]. 
Table 2:- Determination of $\mathrm{Ca}$ and $\mathrm{Fe}$ in the milk

\begin{tabular}{|l|l|l|l|}
\hline Sample & Elements & Present method $\boldsymbol{\mu g} / \mathbf{2 5} \mathbf{~ m l}$ & AAS \\
\hline \multirow{2}{*}{ Milk } & $\mathrm{Ca}$ & 74.611 & 77.468 \\
\cline { 2 - 4 } & $\mathrm{Fe}$ & 0.399 & 0.429 \\
\hline
\end{tabular}

Precision and accuracy:-

The accuracy and precision of the first- derivative simultaneous determination procedures are given in table (3). According to the results, the applicability of the method for the simultaneous determination of iron and calcium in their mixtures was clarified. The recovery and relative standard deviations are also shown in the table (4), indicating that the method was accurate and precise.

Table 3:- Statistical analysis of the determination of $\mathrm{Fe}$ and $\mathrm{Ca}$ in the mixtures by $1^{\text {st }}$-derivative spectrophotometry.

\begin{tabular}{|l|l|l|l|l|l|}
\hline \multirow{2}{*}{ Element determined } & \multicolumn{2}{|l|}{ Other element present } & Slop & Intercept & Correlation coefficient \\
\cline { 2 - 6 } & Element & ppm & & & \\
\hline $\mathrm{Fe}$ & $\mathrm{Ca}$ & 0.4 & 0.97 & 1.266 & 0.992 \\
\hline $\mathrm{Ca}$ & $\mathrm{Fe}$ & 0.4 & 0.6 & 0.8 & 0.991 \\
\hline
\end{tabular}

Table 4:- Precision and accuracy of the method

\begin{tabular}{|l|l|l|l|l|l|l|l|l|l|}
\hline Fe $(\boldsymbol{\mu g} / \mathbf{2 5 m l})$ & SD & \multirow{2}{*}{ RSD\% } & \multirow{2}{*}{ Recovery } & \multicolumn{2}{l|}{ Ca $(\boldsymbol{\mu g} / \mathbf{2 5 m l})$} & SD & RSD & \multirow{2}{*}{ Recovery } \\
\cline { 1 - 6 } Added & Found & & & & Added & Found & & & \\
\hline 10 & 10.14 & 0.288 & 2.8402 & 101.4 & 10 & 10.25 & 0.375 & 3.65 & 102.5 \\
\hline 15 & 15.12 & 0.2863 & 1.893 & 100.8 & 15 & 15.11 & 0.266 & 1.760 & 100.73 \\
\hline 20 & 20.08 & 0.276 & 1.374 & 100.4 & 20 & 20.54 & 0.2356 & 1.147 & 102.7 \\
\hline
\end{tabular}

Nature of the Complex:-

The iron trivalent and calcium were coupled with BPR reagent in basic medium. Job's continuous variation plot of spectrophotometric data from varying the BPR and metal ion concentration at $\mathrm{pH}=11$ showed the existence of a 1 to 2 complexes, and the method of the mole-ratio for Fe (III) to BPR also was found to be 1:2. This is in agreement with $\mathrm{ML}_{2}$-type normal chelate of BPR with metal ions of coordination number 6 [10].

This shows that $\mathrm{Fe}$ (III) and $\mathrm{Ca}$ were coordinated to oxygen atoms of two BPR molecules. Thus, the suggested structure of the complex can be written as follows:

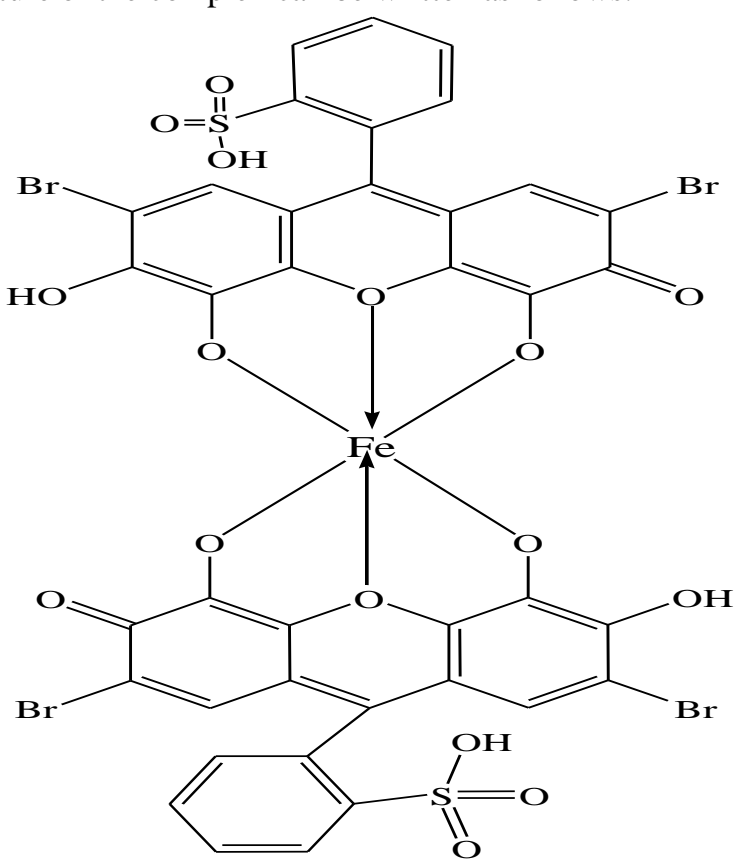

The structure of Fe (III)-BPR complex

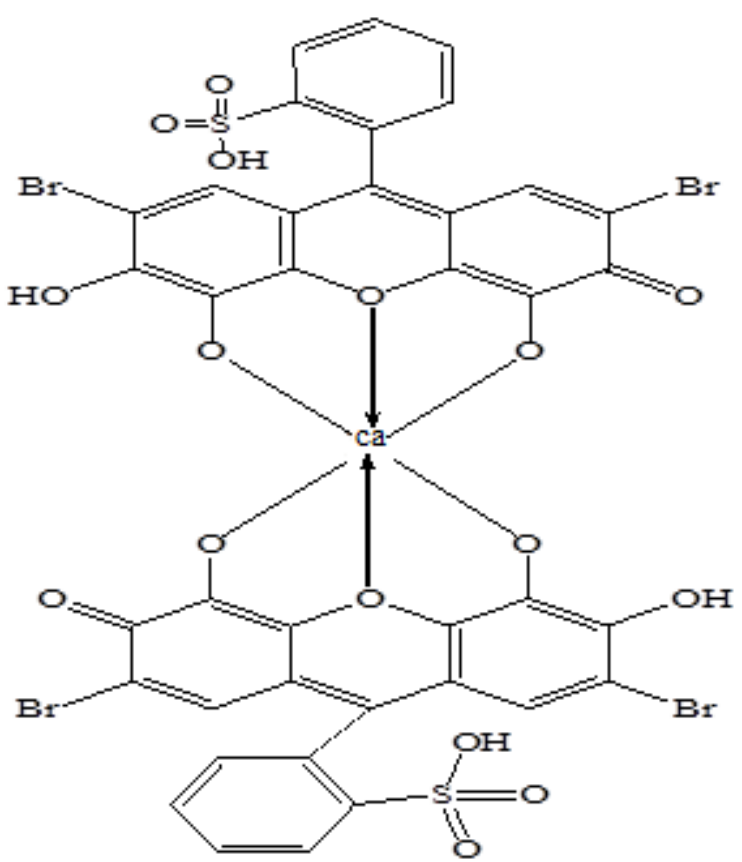

The structure of Ca-BPR complex 


\section{Conclusions:-}

A sensitive and selective method was established for individual and simultaneous determination of iron and calcium using first derivative spectrophotometry with BPR in basic media. The proposed procedures were applied satisfactorily to assays of iron and calcium in a complex mixture in the range $0.4-1 \mathrm{ml}$ of $\mathrm{Fe}$ and $\mathrm{Ca}$, without the need for tedious and time-consuming separation procedures. The proposed method should also be useful for accurate, precise and rapid determination of iron and calcium in various samples. The stability constants (mean of three values) were found to be $1.33 \times 10^{8} \mathrm{~L}^{2} \cdot \mathrm{mol}^{-2}$ and $9.13 \times 10^{11} \mathrm{~L}^{2} \cdot \mathrm{mol}^{-2}$ for Fe-BPR and Ca-BPR complexes respectively which indicates that the complexes are stable.

\section{References:-}

1. L. Antonov, S. Stoyanov, Analysis of the Overlapping Bands in UV-Vis Absorption Spectroscopy, Applied Spectroscopy. 47 (1993) p. 1030-1035.

2. M.A. Ferree and R.D. Shannon, Evaluation of a second derivative UV/visible spectroscopy technique for nitrate and total nitrogen analysis of wastewater samples, Water Research. 35(2001) p. 327-332.

3. H. Abdollahi, M. Shariat Panahi, Simultaneous spectrophotometric determination of iron, cobalt and copper by partial least-squares calibration method in micellar medium, Iranian Journal of Pharmaceutical Research. (2010) p. 207-212.

4. J.M. Estela, V. Cerdà, Flow analysis techniques for phosphorus: an overview, Talanta. 66(2005) p. 307-331.

5. D.D. Perrin, B. Dempsey, E.P. Serjeant, $p K a$ prediction for organic acids and bases, Springer. 1. (1981).

6. C.B. Ojeda, F.S. Rojas, Recent applications in derivative ultraviolet/visible absorption spectrophotometry, Microchemical Journal.. 106(2013) p. 1-16.

7. F. Aberásturi, et al., UV-visible first-derivative spectrophotometry applied to an analysis of a vitamin mixture, J. Chem. Educ. 78(2001) p. 793.

8. M. Petrovich, J. Neto, Direct determination of calcium in milk by atomic absorption spectrometry using flowinjection analysis, Eclética Química,. 32(2007) p. 25-30.

9. R.D. Baker, F.R. Greer, Diagnosis and prevention of iron deficiency and iron-deficiency anemia in infants and young children (0-3 years of age), Pediatrics. 126(2010) p. 1040-1050.

10. V. Chandrasekhar, et al., A Phosphorus Supported Multisite Coordinating Tris Hydrazone P $(\mathrm{S})[\mathrm{N}(\mathrm{Me}) \mathrm{N} \mathrm{CH}$ C6H4-o-OH] 3 as an Efficient Ligand for the Assembly of Trinuclear Metal Complexes: Synthesis, Structure, and Magnetism, Inorganic chemistry,.. 42(2003) p. 5989-5998. 